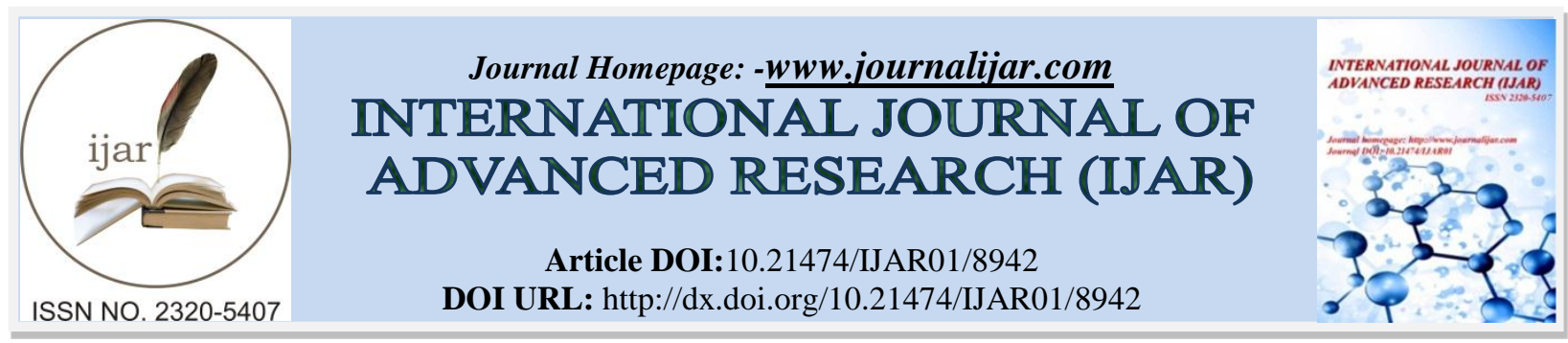

RESEARCH ARTICLE

\title{
COMPARISON OF PATWARDHAN AND PUSH METHOD FOR IMPACTED FETAL HEAD EXTRACTION DURING CAESAREAN SECTION.
}

Reha Rakholia and Geeta Jain.

Department of Obs\&Gynae, Government Medical College, Haldwani.

\section{Manuscript Info}

Manuscript History

Received: 22 February 2019

Final Accepted: 24 March 2019

Published: April 2019

\section{Abstract}

\section{Introduction:-}

The incidence of second-stage Caesarean sections is greater in developing countries, where children are delivered to their homes by traditional birth attendants. The second stage cesarean represents a quarter of all primary cesarean sections ${ }^{1}$. Caesarean sections with complete cervical dilatation with impacted fetal heads are technically difficult because the inferior segment is thinned and edematous and therefore associated with an increased incidence of maternal and fetal morbidity ${ }^{2}$ Delivery of the impacted fetal head in the second stage is technically difficult, and it is a main factor contributing to the associated increased complications ${ }^{3}$. The risks of postpartum maternal complications directly correlate with the duration of the second stage of labour and the mode of delivery ${ }^{4}$.The Patwardhan technique is a unique technique that was introduced by Dr. Patwardhan in 1957 to facilitate delivery of the head deeply affected in caesarean sections of the second stage and have fewer maternal and fetal pathologies. .Many women are referred from the periphery in advanced stages of obstructed labour to our hospital. Extraction and delivery of the fetal head in this situation can be achieved utilizing either abdomino-vaginal approach with head pushing up from the vagina ${ }^{5}$ or Patwardhan technique, where the infant's shoulders are delivered first, then the trunk, breech, limbs and finally the head. So this study was undertaken to compare Patwardhan's technique with the push method and also to evaluate the safety of Patwardhan's technique.

\section{Material and Methods:-}

It is a prospective study including all caesarean sections done in second stage at Tertiary care centre, Haldwani. Patients were divided into two groups: group -1 where baby delivered by Patwardhan technique and group 2 where baby delivered by push technique. Both groups were compared in terms of maternal outcomes as uterine incision extensions, PPH, blood transfusions and neonatal outcomes in terms of their weight, APGAR and NICU stay.

\section{Inclusion criteria:}

Patient with single fetus at term in vertex presentation with full cervical dilatation with deeply impacted fetal head in maternal pelvis.

\section{Exclusion criteria:}

1. Multiple pregnancies

2. Previous caesarean section/myomectomy

3. Antepartum haemorrhage

4. Pregnancy less than 37 weeks 
5. Non cephalic presentation

6. Push technique

More common technique for deeply impacted head during caesarian section in which fetal head is dislodged by pushing it through vagina

Patwardhan technique

1. In case of occipito-anterior and transverse positions with the head deeply impacted in the pelvis, incision is made in the lower uterine segment, shouders are present usually at incision level in deeply engaged head, the anterior shoulder is delivered out by hooking the arm .

2. With gentle traction on shoulder, the posterior shoulder is also delivered out.

3. Next, the surgeon holds the trunk of baby gently with both thumbs parallel to spine and with fundal pressure given by assistant the buttocks are delivered followed by legs.

4. Now the baby's head which is the only part of the foetus which is still inside the uterus, is gently lifted out of the pelvis by making an arc.

\section{Discussion:-}

A prolonged second stage of labour increases the attenuation of lower uterine segment and impaction of foetal head, which gives rise to a thin, easily lacerated lower uterine segment and cervix, which is predisposed to more extensions while delivering foetal head,.Extensions may also occur in cervix and broad ligament, thus increasing incidence of haemorrhage and need for blood transfusions and contributing to maternal morbidity. In our study, extension rate was $18.5 \%$ in "Push" and $1.6 \%$ in Patwardhan thus demonstrating the safety and efficacy of this technique. Less extensions led to decreased chances of traumatic haemorrhage and thus, they decreased need for blood transfusions. Our study shows the significant difference in need for transfusions between the two methods $1.6 \%$ in Patwardhan and 30\% in push.

Extension of incision also has long-term implications on the patients' future obstetric care and may be contraindication to allowing subsequent vaginal delivery .The results of our study were similar to those of a study done by Khosla et al ${ }^{6}$. In this study, no extensions occurred when Patwardhan technique was used.

Our results were also similar to those of the study conducted by Mukhopadhyay et al ${ }^{7}$., In which they concluded that the extent of uterine incision and lesions to surrounding structures during LSCS is common in obstructed labor, when the hand is forcibly introduced into the pelvis to deliver the head that is struck and blocked in the pelvis, because the inferior uterine segment is edematous and fragile. Patwardhan's first shoulder technique avoids this and should be used more widely.

Reeta Bansiwal et $\mathrm{al}^{8}$. study says that there was significant less uterine incision extension in Patwardhan group as compared to push and pull technique $(1 \%, 23.9 \%$ : $\mathrm{p}=0.01)$. The traumatic PPH and blood transfusion was also significantly higher in push and pull method as compared to Patwardhan technique (1.5\%, 22.5\%:p=0.01). The result of the baby was almost similar in both groups study. Manju Lal et al. says that present study shows that incidence of uterine incision extension, and traumatic PPH in group B (pull technique) were significantly higher i.e. 23\% and 25\%, than group A (Patwardhan ) i.e. $4.34 \%$ and $4.34 \%$ respectively Ambreen qureshi et al. states that Patwardhan technique is better and safer technique in delivery of fetus in second stage cesarean sections as compared to Push and Pull methods. Maternal and fetal morbidities are lesser in Patwardhan technique.

Berhan and Berhan reported that push method was associated with nearly 8 fold increased increase risk of lateral or inferior uterine extensions, higher estimated blood loss, greater need of blood transfusion, and increase in mean operating time as compared to Patwardhan technique.

Mitali Mahapatra ${ }^{9}$, studied advantages of Patwardhan technique over push and pull technique are less injury to bladder and ureter, less traumatic PPH, no extension of scar, decrease neonatal injury and birth asphyxia.

Manju Merina Bara et al. says that the patwardhan technique is superior and quite safe method for delivery of baby in second stage cesarean section and has minimal complication if anticipated and done skillfully.

Pradeep Kumar Sahu et $\mathrm{al}^{10}$ did Retrospective analysis of all caesarean sections performed in full dilatation of cervix. All the cases were divided into two groups. Group 1 is the Patwardhan technique and group 2 where the 
baby was delivered as a cephalic or as a breech. Maternal morbidity in terms of uterine extensions, the need for blood transfusions and neonatal morbidity were compared between the two techniques The review of 79 patients revealed a significantly lower number of uterine extensions, as well as the need for blood transfusions with the Patwardhan technique, which meant a decrease in maternal morbidity. However, there were no differences in neonatal outcomes in both groups.

In the study of Partha Mukhopadhyayh Patwardhan technique of first shoulder release was adopted in 50 cases (study group) and compared to 50 cases (control group) in which this method was not used. RESULTS: The extension of the incision, both transverse and vertical, was observed only in four cases in the study group compared to 19 in the control group. Excessive bleeding due to extension of the incision, bladder lesions, need for hysterectomy and need for blood transfusions were much less in the study group. The perinatal result was almost similar in both.

All the results of these studies were similar to those of our study in terms of maternal morbidity (extension of the uterine incision, laceration of the uterine artery, trauma per hour, blood transfusion) neonatal outcome.

\section{up iscussion2}

\section{Results:-}

During study period 116 patients whose caesarean section was done for $2^{\text {nd }}$ stage arrest/obstructed labour. Among 116 cases, 54(47\%) babies were delivered by push method and 62 (53\%) were delivered by Patwardhan technique.Both the Groups were comparable in terms of age and parity of patient. In our study, it was found that majority of the patients were unbooked emergencies

Maternal And Fetal Outcome
\begin{tabular}{|l|l|l|l|}
\hline CHARACTERSTIC & PATWARDHAN & PUSH & Pvalue \\
\hline $\begin{array}{l}\text { Extension of uterine } \\
\text { incision }\end{array}$ & $1[1.6 \%]$ & $10[18.5 \%]$ & 0.002 \\
\hline Uterine artery laceration & $2[3 \%]$ & $11[20 \%]$ & 0.04 \\
\hline Bladder injury & - & - & - \\
\hline Traumatic PPH & $1[1.6 \%]$ & $8[14.8 \%]$ & 0.009 \\
\hline Uterine rupture & - & - & - \\
\hline Blood transfusion needed & $1[1.6 \%]$ & $16[30 \%]$ & $<0.001$ \\
\hline Need for hysterectomy & - & - & - \\
\hline NICU admission & $5[8 \%]$ & $9[17 \%]$ & 0.15 \\
\hline Neonatal death & $1[0.01 \%]$ & $3[0.05 \%]$ & 0.23 \\
\hline ET intubation & $8[13 \%]$ & $11[20 \%]$ & 0.27 \\
\hline APGAR at 1min(<=7). & $8[13 \%]$ & $11[20 \%]$ & 0.27 \\
\hline APGAR at 5min.(<=7) & $03[05 \%]$ & $05[11 \%]$ & 0.18 \\
\hline
\end{tabular}

Out of 116 cases, $78 \%$ of them were from rural areas. Though $22 \%$ were from urban, all cases were emergency admissions.Majority patients were referred from primary health centres. Some of the patients werereferred due to late recognition of inherent obstetric complication and some due to complication during the course of labour. $70 \%$ of the patients were illiterate and hence their ignorance regarding the standard of health and nutrition and lack of knowledge of antenatal care and hospital delivery contributed largely in not taking medical care.

The above study shows that $78 \%$ of patients were from lower-socio economic status. Factors influencing maternal mortality are unbooked cases, extremes of age in reproductive period, high parity\& low socio economic status.In the present study most of the babies had birth weight in the range of $2.5-3 \mathrm{kgs}$. In our study $12 \%$ of the neonates required NICU admission. The duration of NICU stay in $60 \%$ of the cases was more than 3 days, higher in advanced cases than those who were referred earlier. The fetal salvage was directly related to the degree of obstruction rather than methods of delivery.Baby outcome was almost similar in both the groups.

In our study there were a total of 116 patients whose cesarean section was performed for the second stage / obstructed labor. Among 116 cases, 54 (47\%) children were delivered with the push method and $62(53 \%)$ were delivered with the Patwardhan technique. Extensions of the uterine incision were significantly less $1(1.6 \%)$ in the 
Patwardhan group compared to the push technique 10(18.5\%). The traumatic PPH 1 (1.6\%) in Patwardhan 8 $(14.8 \%)$ in the push technique.

The requirement for blood transfusion was also significantly lower in the Patwardhan technique than the conventional push method $1(1.6 \%)$ and $11(30 \%)$, respectively. Tears of the uterine artery $2(3 \%)$ in Patwardhan and $11(20 \%)$ in the Push technique. The result of the child was almost similar in both groups.

\section{Conclusion:-}

The Patwardhan manoeuvre needs expertise but is safe and has minimal complications compared to the push method if anticipated and done skillfully. It is easy to learn and needs to be more widely publicized and utilized.It has been shown that the method of delivery of Patwardhan for the second stage of labour confers a considerable advantage in the prevention of maternal morbidity in our institution.

Our results support the fact that the Patwardhan method could be a useful maneuver in the intraoperative disengagement of the fetal head, when it is in the second stage caesarean section and we believes that the Patwardhan maneuver can be selectively practiced as a primary technique in patients with a deeply impacted head to reduce maternal and fetal morbidity.

\section{References:-}

1. Evaluation of cesarean delivery, The American College of Obstetricians and Gynecologists Women's Health Care Physicians, 409 12th Street, SW • PO Box 96920 • Washington, DC 20090-6920 ACOG 2000.

2. Asicioglu O, Gungorduk K, Yildirim G, Asicioglu BB, Gungorduk OC, Ark C, et al. Second-stage vs first-stage caesarean delivery: comparison of maternal and perinatal outcomes. J Obstet Gynaecol 2014;34:598-604. 4

3. Saha PK, Gulati R, Goel P, Tandon R, Huria A. Second stage caesarean section: evaluation of patwardhan technique. JCDR 2014;8:93-5.

4. Stephansson O, Sandstrom A, Petersson G, Wikstrom AK, Cnattingius S. Prolonged second stage of labour, maternal infectious disease, urinary retention and other complications in the early postpartum period. BJOG 2015; doi: 10.1111/1471-0528. 13287. [Epub ahead of print].

5. Veisi F, Zangeneh M, Malekkhosravi S, Rezavand N (2012) Comparison of "push" and "pull" methods for impacted fetal head extraction during cesarean delivery. Int J Gynaecol Obstet 118: 4-6.

6. Khosla AH, Dahiya K, Sangwan K. Caesarean section in wedged head. Ind J Med Sci 2003; 57: 187-91

7. Mukhopadhyay P, Naskar T, Dalvi R, Hazra S, Bhattacharya D, Evaluation of Patwardhans technique: A four year study in rural teaching hospital. J. Obstet gynacol Ind 2005; 55(3) :244-

8. Bansiwal R et al. Int J Reprod Contracept Obstet Gynecol. 2016 May;5(5):1562-1565

9. Mahapatra M. Patwardhan's technique: it's impact on maternal and fetal outcome. YUVA Journal of Medical Sciences. 2015;1(2):26-7

10. Pradip Kumar Saha et al., Second Stage Caesarean Section: Evaluation of Patwardhan Technique. Journal of Clinical and Diagnostic Research. 2014;8(1):93-5. 24. Ajith virkud. Video clip: Patwardhan manoeuvre. 